\title{
CFD-modeling of fume formation in kraft recovery boilers
}

\author{
AINO LEPPÄNEN, ERKKI VÄLIMÄKI, ANTTI OKSANEN, AND HONGHI TRAN
}

ABSTRACT: A computational fluid dynamics (CFD) model was developed to simulate alkali metal chemistry and fume particle formation in a kraft recovery boiler. The modeling results were partially validated against previously obtained field measurements. The model provides information about fume composition, chlorine and potassium enrichment factors, and particle mass concentration at different locations in the boiler.

Application: The modeling method presented in this article can help boiler designers to better understand how the local conditions affect the alkali metal chemistry and fume formation in kraft recovery boilers. The method can help predict the potential for corrosion and fouling under different operational conditions.

B lack liquor contains large amounts of compounds of the alkali metals sodium and potassium, which have a significant effect on the operation of kraft recovery boilers. These ash-forming alkali metal compounds are problematic in the gaseous phase, in which they can contribute to corrosion, and in the particle phase, in which they can cause fouling and plugging of the boiler. The relationships among the flue gas temperature, the flow field, the chemistry, and fume formation must be investigated to understand the behavior of alkali metals in the boiler.

This paper presents a computational fluid dynamics (CFD) model that captures the alkali metal behavior and fume formation in a kraft recovery boiler. The model focuses on submicron-size fume particles because they constitute the largest fraction of the particle mass in the superheater area of the boiler [1]. In contrast with the larger $(>100 \mu \mathrm{m}$ [2]) carryover particles, fume particles are able to flow with the flue gas. Because they also contain larger amounts of condensed alkali chlorides than are present in carryover particles, they may be involved in the fouling and corrosion of the tube surfaces in the superheater area. In experiments by Skrifvars et al. [3], the addition of even small amounts of alkali chlorides to alkali sulfate salts triggered corrosion.

Alkali chlorides (sodium chloride and potassium chloride) play a role in the fouling of the tube surfaces because they lower the melting temperatures of the particles and increase their liquid content [4], making it easier for them to form deposits on boiler surfaces. Deposits decrease the heat transfer rate and, in severe cases, may plug the flue gas passages. If molten, they also might accelerate tube corrosion.

The CFD approach has been used widely in combustion and flow modeling. This study applies it to recovery boilers, with a focus on the alkali metal compounds and the physical and chemical phenomena associated with them, including chemical reactions and fume formation. The aim is to develop a model capable of predicting the behavior of the alkali com- pounds under different operating conditions. The model uses three commercial programs: FLUENT [5]; FactSage and its Equilib application [6,7]; and the Fine Particle Model (FPM) [8]. The FPM is an aerosol dynamics model that runs together with FLUENT. It has been applied primarily to atmospheric aerosol modeling [9], but it also can be used to simulate chemical reactors.

In our previous paper [10], we introduced a model that incorporates equilibrium chemistry and fine particle formation into CFD simulations to gain insight into fouling and corrosion in kraft recovery boilers. However, the earlier model covered only the furnace area of the boiler. The model presented in this paper is an extended version of the previous model. The new model covers the furnace and the superheater areas, and considers a wider range of ash-forming compounds, including sodium and potassium carbonates and hydroxides, in addition to alkali sulfates and chlorides.

A similar model, called the aerosol behavior in combustion (ABC) model, was developed by Jokiniemi et al. in 1994 $[11,12]$. The ABC model combines the simulation of local gas phase chemical equilibria with the modeling of the formation, growth, and deposition of aerosol particles. It was first validated in experiments with pulverized coal combustion [11] and later with kraft recovery boilers [12]. The difference between the two models is that the ABC model is one-dimensional and uses the nodal point method to discretize the particle size distribution, whereas our model is three-dimensional and uses the modal aerosol dynamics (MAD) model to represent the size distribution. The MAD approach is ideal for simulating complex processes because it can provide fast and accurate results by assuming a certain particle size distribution [13].

Several researchers have applied CFD modeling to the deposition of carryover particles [14,15]. However, because of their much larger size, carryover particles behave differently from the smaller fume particles. The main mode of deposition 
of carryover particles is inertial impaction, whereas for fume, it is thermophoresis, in which fine particles in the hot combustion gas are transported toward the colder tube surface. Although the deposition of fume particles is not included in the current model, this is not expected to have a significant effect on the results because the amount of fume depositing on the tube surfaces in the superheater area is small: only $4 \%$ of the fume particle mass, according to one approximation [16].

In this paper, the new CFD model was applied to simulate fume formation and alkali metal chemistry in a typical recovery boiler, using the parameters from an actual boiler in South America. The simulation results were partially validated against the field measurements of Tavares and Tran [17], who used a fume deposition probe to investigate the composition of fume at different locations in a North American recovery boiler. More complete validation was not possible because the operating parameters of the North American boiler are not available, so the simulation is based on one boiler, but the results are compared against measurements from another. The simulation also provides information about the potential for fouling and corrosion in different locations in a kraft recovery boiler based on particle composition, particle mass concentration, enrichment factors, and flue gas composition.

\section{THE MODEL}

\section{Combustion and alkali metal release}

The modeling of fume formation and the alkali metal chemistry is built on a FLUENT boiler model that considers the injection, pyrolysis, and combustion of black liquor droplets, but not the char bed and smelt reactions. The heat transfer surfaces in the superheater area are assumed to be at constant temperatures, which are based on typical empirical values. The temperature and velocity distributions resulting from the combustion reactions and the boundary conditions of the model are "frozen" before the calculation of the alkali compounds begins. This one-way coupling is possible because the alkali compounds do not change the temperature field appreciably.

The model consists of two three-dimensional computational grids: one covers the furnace area up to the bullnose level, the other covers the space between two superheater platens. Each grid contains about 400,000 computational cells, and the superheater grid is much denser than the furnace grid. Although the furnace and the superheater area are modeled separately, the results obtained for the furnace grid are transferred to the superheater grid. Momentum, heat, and mass are conserved with the help of the Reynolds-averaged Navier-Stokes (RANS) equations, and a steady-state solver is applied. The pressure field is calculated using the SIMPLE algorithm. The turbulence model used is the realizable $\mathrm{k}-\varepsilon$ model with standard wall functions, and the interaction between turbulence and chemistry is calculated according to the finite-rate/eddy-dissipation model. The discrete ordinates method is used for radiative heat transfer.

\begin{tabular}{|c|c|}
\hline Element & Release (\%) \\
\hline $\mathrm{Na}$ & 12 \\
\hline $\mathrm{K}$ & 17 \\
\hline $\mathrm{S}$ & 21 \\
\hline $\mathrm{Cl}$ & 34 \\
\hline
\end{tabular}

\section{The release factors used in the model.}

Modeling alkali metal compounds requires that the simulated black liquor contain the inorganic elements (sodium, potassium, sulfur, and chlorine) found in black liquor. The actual modeling of the alkali metal compounds begins at the point after the black liquor is injected into the boiler and pyrolyzed. The model relies on release factors for the different elements (i.e., the fractions of the various elements entering the gas stream), using them to determine the amount of black liquor entering the gas stream and the amount remaining in the char bed. According to Tamminen et al. [18], release associated with the char bed can be excluded because, for the inorganic elements, release from in-flight black liquor droplets is the most important release mechanism.

The release factors used in this model are based on published data $[1,19,20]$. For simplicity, only one value is assumed for each element (Table I). In practice, however, the temperature of the lower furnace can affect the release factor and the enrichment factor for each element $[21,22]$. Unfortunately, there is no consensus in the literature about the values of the release factors. However, recent measurements using an entrained flow reactor [23] may give reasonably reliable values, which will be considered in future work.

\section{Alkali metal reactions}

After the black liquor combustion and release of the inorganic elements are modeled, the reactions between the alkali metal compounds are simulated at a fixed temperature and in a fixed flow field. The reactions, which were described by Jokiniemi et al. [12], involve the sodium compounds $(\mathrm{NaCl}$, $\mathrm{NaOH}, \mathrm{Na}_{2} \mathrm{CO}_{3}$, and $\mathrm{Na}_{2} \mathrm{SO}_{4}$ ), potassium compounds $(\mathrm{KCl}$, $\mathrm{KOH}, \mathrm{K}_{2} \mathrm{CO}_{3}$, and $\mathrm{K}_{2} \mathrm{SO}_{4}$ ), sulfur dioxide, and hydrogen chloride, together with oxygen, water, and carbon dioxide. The reactions are modeled as equilibrium reactions because the temperature in the furnace is sufficiently high that they reach equilibrium quickly [24]. However, Christensen and Livbjerg [25] claim that, under this equilibrium assumption, the sulfation of potassium chloride in the combustion of straw is overestimated, suggesting that it might be more accurate to use a kinetically limited reaction rate for sulfation in black liquor combustion as well. In fact, Jöller et al. [26] used a kinetic approach to model gaseous sulfate formation in different biomass-fired boilers, considering the reaction from sulfur dioxide to sulfur trioxide to be the rate-limiting step, and noting that $820^{\circ} \mathrm{C}$ is the limit below which the equilibrium assumption does not hold. However, because of the difficultly in finding a reaction rate expression for sulfation reactions, the equilibrium approach is used in this model, despite the 
uncertainty about its applicability. Two observations support the use of the equilibrium approach: 1) the residence times in the kraft recovery boiler are relatively long, and 2) most of the sulfation reactions occur in the boiler furnace, where the temperature is above $820^{\circ} \mathrm{C}$.

The extents of the equilibrium reactions between the alkali metal compounds are calculated for each computational cell, taking into account the temperature and the amounts of inorganics in that cell. The calculations are performed with FactSage and its Equilib application, which uses the Gibbs free energy minimization method to calculate the equilibria in multicomponent and multiphase systems [7,27]. The equilibrium reactions are assumed to occur mainly under oxidizing conditions. A simplified model also is used to simulate the reducing conditions in the reducing zone below the tertiary air level: where the sulfation of hydroxides is limited when the amount of carbon monoxide in the computational cells exceeds $5 \%$ of the total flue gas mass.

\section{Fume formation}

The formation of fume particles is modeled with the help of the FPM [8], which includes aerosol dynamics functions such as nucleation, condensation, and coagulation. The FPM is based on MAD models, which represent an aerosol size distribution as a group of distinct aerosol populations, each of which is described by an analytical modal distribution function [13]. The FPM uses the lognormal distribution function, which is the usual choice for aerosol populations. The distribution function is substituted into the general dynamic equation, which expresses the changes in the size distributions as a result of different aerosol processes [28]. The FPM differs from many other particle models in that it simulates the formation and interaction of particles in the Eulerian reference frame by considering populations of particles [8]. In contrast, the discrete particle model in FLUENT [5] uses the Lagrangian reference frame and solves for the trajectories of individual particles.

The main processes modeled by the FPM are nucleation, condensation, and coagulation. Nucleation refers to the formation of new particle seeds from saturated vapor in the absence of condensation nuclei [29]. Although the FPM has a function for classical homogeneous nucleation, it is not reliable [9,30]. This is not surprising because the modeling of nucleation is generally considered difficult; one reason is that the rate of homogeneous nucleation is sensitive to the surface tension of the nucleating compounds [25].

To simplify the current model, nucleation is not simulated; instead, a quantity of inert particle nuclei having negligibly small mass is introduced into the flue gas. This approach is justified because it is not known whether particle formation in the recovery boiler starts as a result of nucleation or as a result of condensation on small inert particle seeds, such as metal oxides [12]. Jokiniemi et al. [12] found metal oxides in the aerosol samples they collected from recovery boilers, although the amount was much smaller than in samples from coal-fired boilers. Accordingly, they claimed that the particle size distribution would not be significantly different if nucleation were modeled, so their $\mathrm{ABC}$ model uses an inert particle nuclei approximation. Excluding nucleation also is justified by the observation that if particle nuclei are already present, vapors will condense on them rather than form new nuclei on their own [31]. This is because condensation requires a saturation ratio just above 1 , whereas nucleation requires saturation ratios between 2 and 10 [29].

Condensation, which is easier to model than nucleation, is the most important process in fume modeling because of its primary role in determining the fume particle mass and composition. Fume also can condense on carryover particles, but according to Eskola et al. [16], the amount of condensed matter on carryover particles is negligible because of their low total surface area. From this perspective, excluding the carryover particles should not have much effect on the calculated values of the condensed particle mass.

To model condensation, it is necessary to know the vapor pressures for the condensing compounds. The current model uses the vapor pressures of pure compounds, although mixing two or more molten compounds could lower the vapor pressure of the mixture. With this in mind, Eskola et al. [16] used Raoult's law to modify the ABC model to approximate vapor pressures of mixed condensing species on the surface of molten particles. However, this approach was not applied here because Eskola et al. [16] did not estimate how much the vapor pressures change as a result of the modification.

In addition to condensation, coagulation of fine particles can be modeled with the FPM. Coagulation is the formation of new spherical particles from collisions of molten particles, whereas agglomeration is the formation of nonspherical particles from collisions of solid particles $[1,31]$. However, because it is not possible to model agglomeration with the FPM, and coagulation does not have any effect on the particle mass concentration, for the moment, these processes are not considered in the model. Moreover, as mentioned, the model does not yet include particle deposition because its effect on the total fume mass is expected to be insignificant.

\section{RESULTS AND DISCUSSION}

This section presents some of the modeling results and compares them to the measurements obtained for an actual boiler by Tavares and Tran [17].

\section{Black liquor composition}

Table II shows the modeled black liquor composition, but unfortunately, the fuel composition of the actual boiler is not available.

\section{Boiler temperature}

Temperature has a significant effect on the behavior of alkali metal compounds and the formation of fine fume particles. Figures 1 and 2, respectively, present the modeled temperature distributions in the furnace and between two superheater platens in the middle of the boiler. 


\begin{tabular}{|c|c|}
\hline Element & Dry matter (wt-\%) \\
\hline $\mathrm{C}$ & 33 \\
\hline $\mathrm{O}$ & 34 \\
\hline $\mathrm{H}$ & 3.2 \\
\hline $\mathrm{N}$ & 0.1 \\
\hline $\mathrm{Na}$ & 18 \\
\hline $\mathrm{S}$ & 6.1 \\
\hline $\mathrm{K}$ & 4.0 \\
\hline $\mathrm{Cl}$ & 0.6 \\
\hline
\end{tabular}

II. Modeled black liquor composition expressed as dry matter mass fractions.

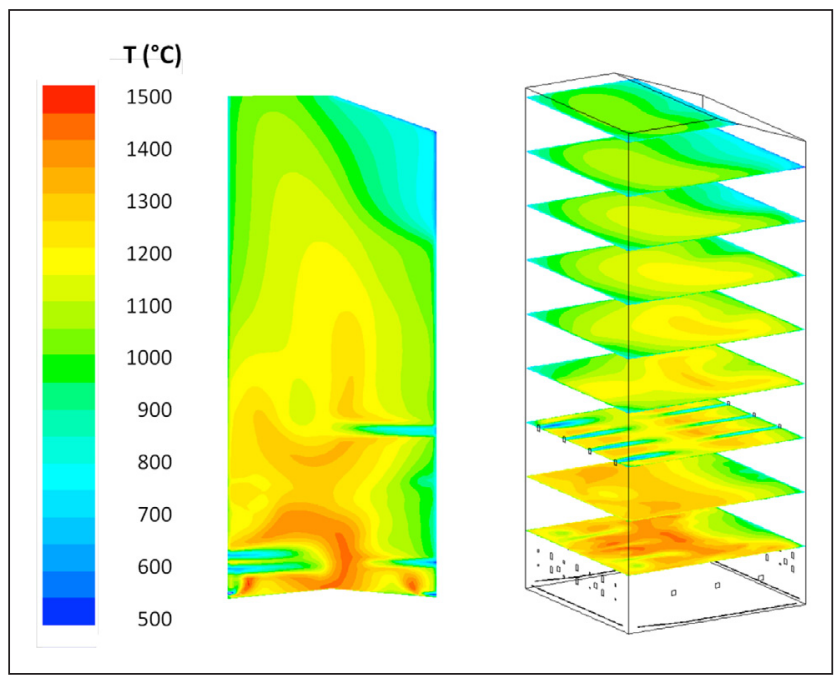

\section{Modeled temperature distribution in the furnace.}

In Fig. 2, a recirculation zone can be identified just above the bullnose; this has been measured in actual boilers. The recirculation of the flue gas causes the temperature to drop by as much as $300^{\circ} \mathrm{C}$, which has a negative effect on the rate of heat transfer from the flue gas to the steam because heat starts to flow in the opposite direction [32]. However, it is not easy to find a steady-state solution with the RANS method: sometimes a recirculation zone is seen, but sometimes it disappears.

Temperature distribution has a significant effect on the modeling results because fume formation depends on the ratio of the partial vapor pressure $p_{v}$ to the saturation vapor pressure $p_{s}(T)$ of a condensing compound. The saturation ratio $S=p_{v} / p_{s}(T)$ has to be greater than 1 for condensation to occur [29], so particle mass grows mainly in the low temperature areas where the saturation vapor pressures are low.

\section{Fume composition}

In their field measurements, Tavares and Tran [17] used an encapsulated fume measurement probe to prevent carryover particles from depositing on the tube. They measured fume deposition for $10 \mathrm{~min}$ at different boiler locations, most of which were in the superheater area. The deposit collecting

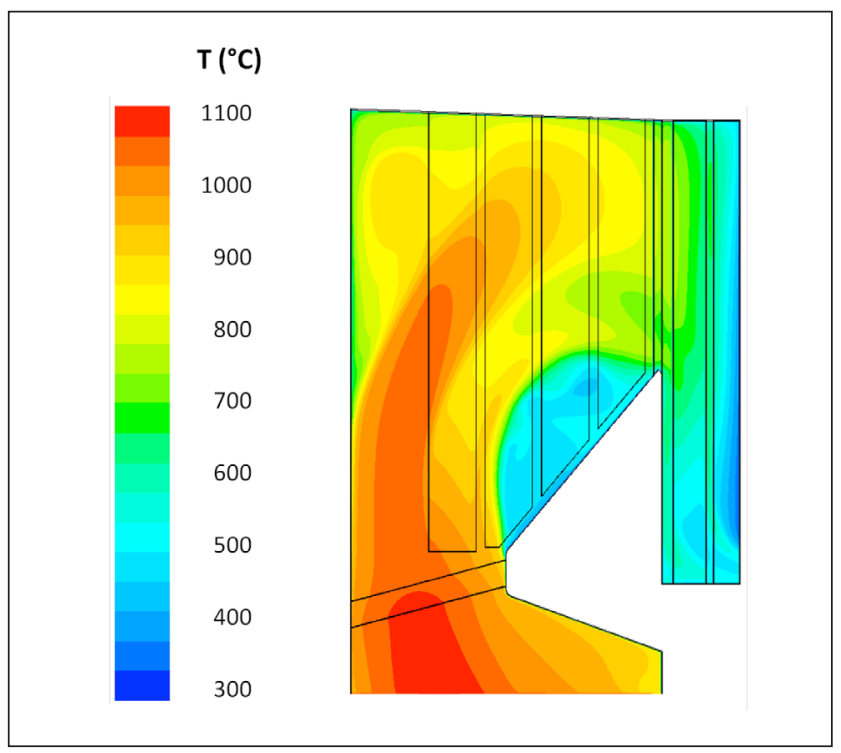

2. Modeled temperature distribution between two middle superheater platens.

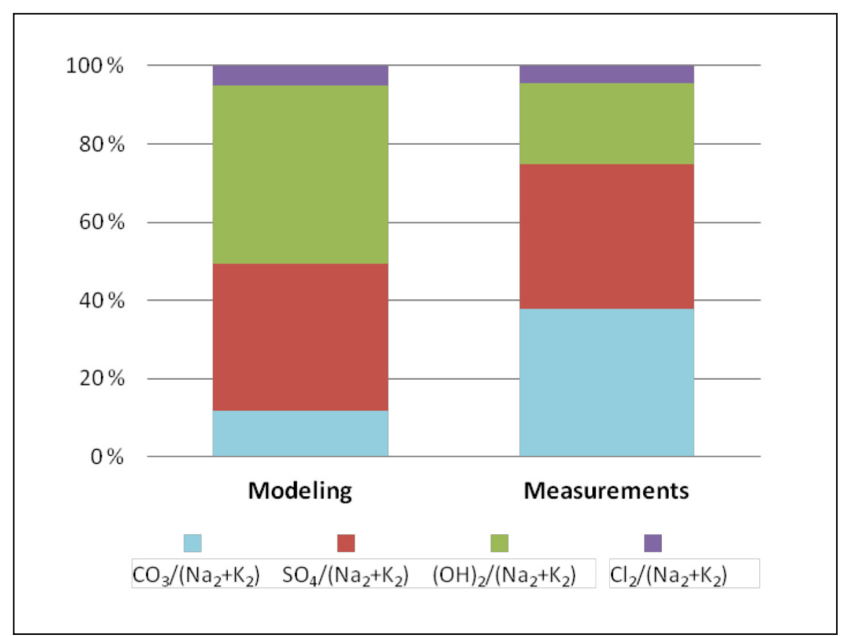

\section{Comparison of lower furnace modeling results to the measurements of [17].}

probe was not cooled during the tests in the superheater region, but in the lower furnace, the temperature was so high that the probe had to be cooled to prevent corrosion. However, because it is difficult to model a cooled surface, the modeling results differ significantly from measurement results for the tests in the lower furnace. Figure 3 compares the two sets of results in terms of the molar ratios of the various anions $\left(\mathrm{CO}_{3}, \mathrm{SO}_{4},(\mathrm{OH})_{2}\right.$, or $\left.\mathrm{Cl}_{2}\right)$ to the combined total of the cations $\left(\mathrm{Na}_{2}+\mathrm{K}_{2}\right)$.

As can be seen from Fig. 3, the results for sulfates and chlorides correspond quite well, but those for hydroxides and carbonates do not. The difference probably arises because carbonate formation is strongly temperature dependent, and the temperature was probably lower at the measurement location than at the modeling location because the actual boiler was operated at only $89 \%$ of its rated capacity. The hydroxides also might have reacted to form carbonates inside the cooled mea- 


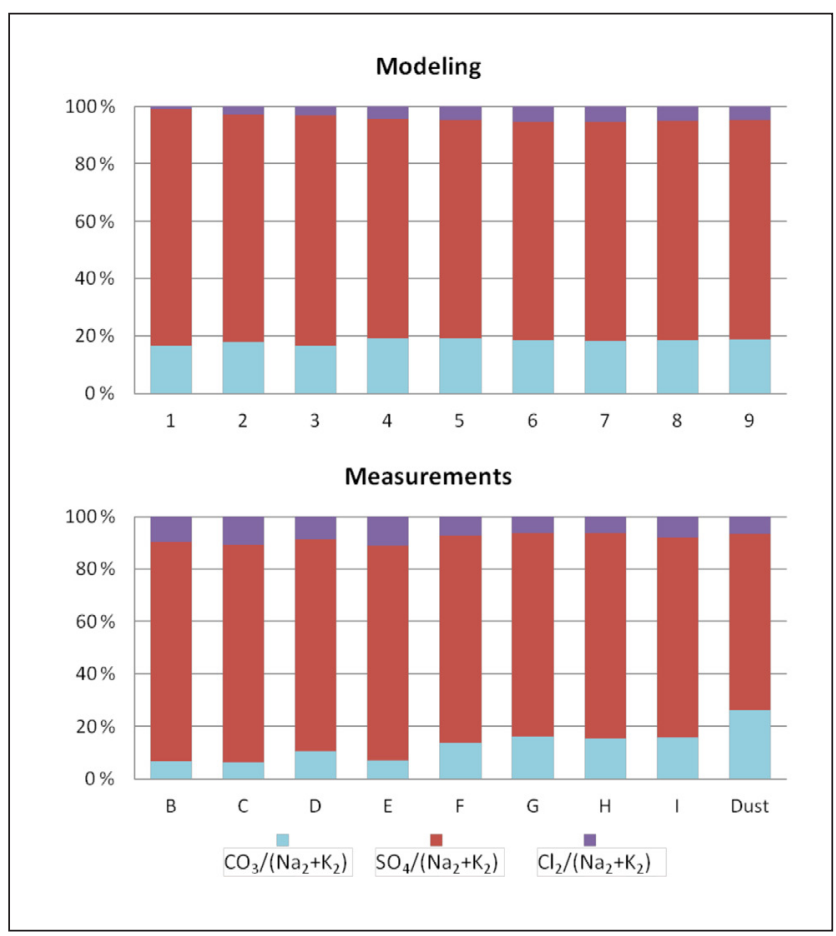

\section{Comparison of the superheater modeling results and the measurements obtained by [17].}

surement probe. Furthermore, the measurement point used by Tavares and Tran [17] was next to a black liquor gun port and below the tertiary air, so the conditions most likely were reducing. Although the model takes into account the reducing conditions and the cooling of the probe by assuming incomplete sulfation and the condensation of all the ash-forming compounds on the cooled probe, it cannot compensate for the reactions that take place inside the cooled probe. Because the model can represent only the chemical equilibrium in the surrounding gas, the calculated results are somewhat different from the measurement results.

In contrast with the lower furnace results, the modeling results for the superheater area are in good agreement with the measurements. This is because the modeled conditions at these locations, especially temperature, were similar to the actual conditions. Figure 4 (lower) shows the composition of the fume deposits collected at eight different points (labeled $B$ to $I$ ) and of the precipitator dust [17]. Modeling also was performed for nine different points (1 to 9) at approximately the same locations as those used for the field measurements. Figure 4 (upper) shows the results.

The measurements and modeling show that the amount of chlorides is around $3 \%-10 \%$ of the total anions, although the modeled amount of chlorides is somewhat lower (Fig. 4). With the exception of the precipitator dust, the values for carbonates are similar (10\%-20\%). According to the measurements, the amount of carbonates increases toward the end of the flue gas flow, with a high fraction (25\%) in the final dust, but the modeling results do not show a similar pattern. However, discrepancies in direct comparisons of the two boilers are not surprising:

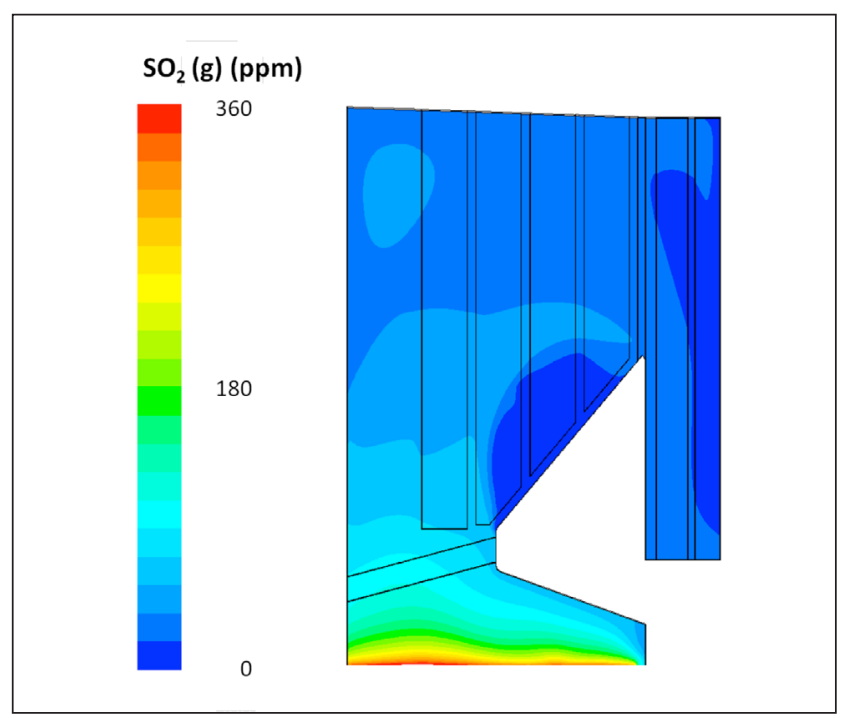

5. Distribution of $\mathrm{SO}_{2}(\mathrm{~g})$ in the superheaters.

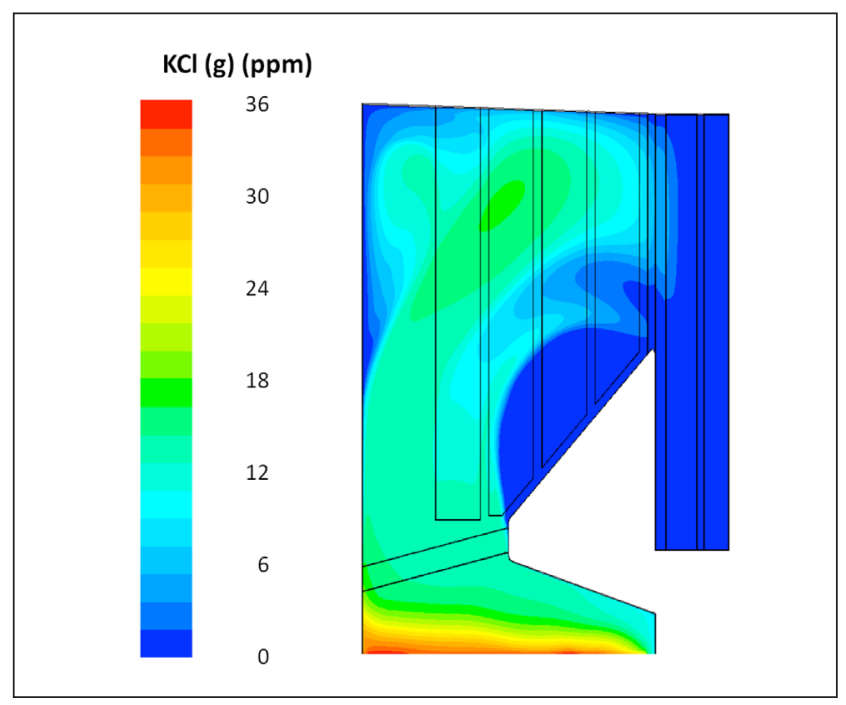

6. Distribution of $\mathrm{KCl}(\mathrm{g})$ in the superheaters.

it seems that the carbonate content in the ash depends on individual boiler operation and black liquor composition.

\section{Gas composition}

The model calculates not only the composition of fume, but also the composition of the flue gas. The reactions of the alkali metal compounds and their condensation onto particles affect the amount of alkali compounds in the flue gas. For example, when the flue gas moves toward the generating bank and the economizer sections of the boiler, sulfur dioxide almost completely disappears because of sulfation reactions. The amount of gaseous potassium chloride also decreases, from around $35 \mathrm{ppm}$ below the bullnose to zero at the boiler bank, because it condenses onto particles. Figures 5 and 6 show the $\mathrm{SO}_{2}(\mathrm{~g})$ and $\mathrm{KCl}(\mathrm{g})$ distributions between the two middle superheater platens. 
Based on the fume particle composition shown in Figs. 3 and 4, the model also can predict the enrichment factors for potassium and chloride in the precipitator ash. The enrichment factor calculated for potassium is 1.3 , whereas for chlorine, it is around 2.5. These values are realistic because enrichment factors typically are between 1.5 and 3 [33,34], so it can be assumed that the release factors used for potassium and chlorine are reasonable.

\section{Fume mass}

Although the model can simulate the mass of the fume particles in the gas flow, it cannot simulate the mass of the carryover particles. In practice, however, the carryover mass may affect the total particle mass. Moreover, the measured particle mass at the boiler exit also might include the particle mass removed by the sootblowers, which the model does not consider either. Figure 7 shows the particle mass distribution predicted by the model.

Particle mass seems to accumulate in the recirculation zone, as can be seen in Fig. 7. In addition to the lower velocity in this area, the lower temperature in the recirculation zone, which increases condensation, also contributes to accumulation. Another location where the particle concentration increases significantly is near the screen, where the hot flue gas (around $1000^{\circ} \mathrm{C}$ ) passes through the much colder screen $\left(320^{\circ} \mathrm{C}\right)$ and cools down, which increases condensation onto particles. In actual boilers, however, direct condensation onto the surface of the tubes also might occur, but this has yet to be included in the model.

The modeling results in Fig. 7 show that the particle mass concentration is nearly constant, except in the screen area and the recirculation zone around the bullnose level. However, published measurements $[17,35]$ indicate that an increase in the particle mass occurs abruptly at a location near the boiler

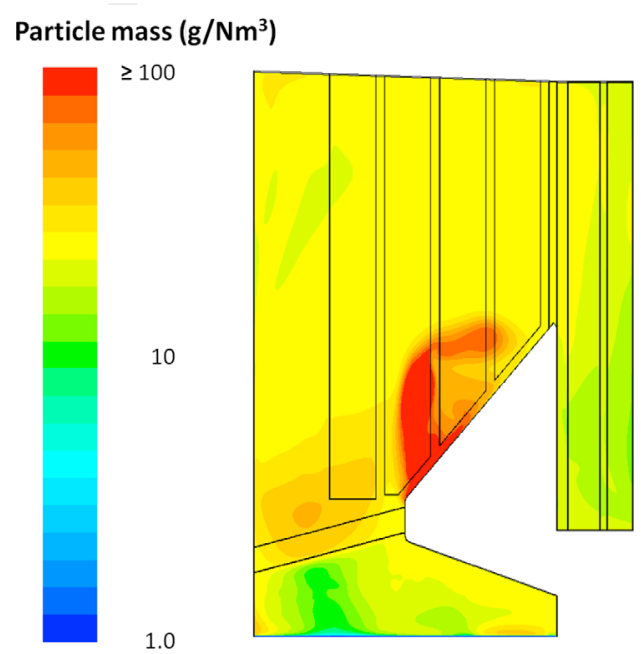

7. Particle mass concentration in the superheaters as given by the model. bank inlet, where the gas temperature was around $550^{\circ}$ $650^{\circ} \mathrm{C}$. This observation is interesting. Because the lowest melting temperature of the ash-forming compounds in a boiler is $775^{\circ} \mathrm{C}$ for potassium chloride [17], all the ash-forming compounds are expected to condense before the flue gases cool to this temperature. Tavares and Tran [17] explain this observation by proposing a "supercooling" effect, in which the formation of condensation nuclei begins only when the temperature is significantly below the boiling point of the condensing compounds. This would be the case, according to classical nucleation theory [29], if no particle seeds were present before the condensation of alkali vapors; however, it would not be the case if carryover particles and metal oxides were present throughout in the boiler. Because the model assumes the presence of seed particles, it predicts that particle formation will start much earlier than was observed by Tavares and Tran [17]. Clearly, this issue requires more theoretical and experimental investigation because measurements by Mikkanen [1] indicate that significant amounts of particle mass appear before the gases reach the boiler bank. Furthermore, a low rate of deposition is not necessarily related to a low concentration of fume in the gas stream [36].

\section{CONCLUSIONS}

The results of the model presented in this paper were compared with the recovery boiler measurements of Tavares and Tran [17]. The results for fume particle composition are in good agreement, especially as concerns the fume composition at the superheater area. However, the new CFD model still has several limitations. First, the location at which particle mass formation occurs is uncertain because the results differ significantly from the measurements of Tavares and Tran [17]. Moreover, the model relies on many simplifications, which might cause the results to deviate from reality. The release factors for inorganic elements also might need to be chosen with greater care. In addition, the equilibrium chemistry approach should be assessed critically because it is not reliable for temperatures below $820^{\circ} \mathrm{C}$ [26]. Another weakness of the model is the simplified treatment of the reducing zone, which casts doubt on the results for the lower furnace. Nonetheless, the model appears to work well in the superheater region, where the tubes are more vulnerable to fouling and corrosion.

Validation of results is a challenge inherent in all CFD models. It is especially difficult to measure aerosol particles in a hot environment because the particle populations can change during measurement as a result of phenomena such as condensation. Even temperature measurements are problematic because factors such as turbulence and sootblowing make the situation in the boiler unstable. This is an obstacle to fine particle modeling; small changes in temperature can have significant effects on particle mass and composition.

Despite these challenges, future work will include validation of the boiler model against boiler measurements. The model will continue to be developed, and potentially expanded to consider the deposition of fume particles resulting from 
thermophoresis. Another process that could be modeled is the direct condensation of vapors on cool surfaces, particularly at locations where the flue gas temperature is high and the tube surface temperature is low.

The ultimate goal is to use the model to optimize boiler design and operation. A sensitivity analysis could help explain how changes in the lower furnace temperature, black liquor composition, or the design of the air delivery system might affect the concentration of gaseous alkali compounds in the flue gas and the fume particles. TJ

\section{ACKNOWLEDGEMENTS}

The authors express their appreciation to Metso Power Oy, the Finnish Foundation for Technology Promotion (TES), Kaartokulman erikoisrahasto, Walter Ahlströmin säätiö, and the Finnish Graduate School in Computational Fluid Dynamics in the Academy of Finland for financing this project. They also gratefully acknowledge the contributions of J. Pyykönen, who proposed the principles on which the model is based, and of V.-P. Heikkilä for developing the computational mesh and the combustion model.

\section{LITERATURE GITED}

1. Mikkanen, P., "Fly ash particle formation in kraft recovery boilers," Ph.D. thesis, Technical Research Centre of Finland, Espoo, Finland, 2000.

2. Wessel, R.A., Baxter, L.L., Shaddix, C., et al., Int. Chem. Recovery Conf., TAPPI Press, Atlanta, GA, USA, 2004, p. 363.

3. Skrifvars, B.-J., Backman, R., Hupa, M., et al., Corros. Sci. 50(5): 1274(2008)
4. Janka, K., Raukola, A., Wallén, J., et al., TAPPI Eng. Conf., TAPPI Press, Atlanta, 2000, p. 897

5. Fluent (ANSYS), Inc., FLUENT 6.3 software documentation, ANSYS, Lebanon, NH, USA, 2006.

6. Bale, C.W., Chartrand, P., Degterov, S.A., et al., CALPHAD 26(2): 189(2002).

7. Thermfact/CRCT and GTT-Technologies, FactSage modules: The Equilib module - (regular features), Thermfact/CRCT, Montreal, OC Canada, and GTT-Technologies, Aachen, Germany, 2009. Available online at www.crct.polymtl.ca/factsage/fs_equilib.php.

8. Particle Dynamics GmbH, "Fine Particle Model (FPM) for FLUENT user's guide," Particle Dynamics GmbH, Leipzig, Germany, 2003.

9. Uhrner, U., von Löwis, S., Vehkamäki, H., et al., Atmos. Environ. 41(35): 7440(2007).

10. Leppänen, A., Välimäki, E., and Oksanen, A., TAPPI J. 11(7): 9(2012).

11. Jokiniemi, J.K., Lazaridis, M., Lehtinen, K.E.J., et al., J. Aerosol Sci. 25(3): 429(1994)

12. Jokiniemi, J., Pyykönen, J., Mikkanen, P., et al., TAPPI J. 79(7): 171(1996).

13. Whitby, E. and McMurry, P., Aerosol Sci. Technol. 27: 673(1997).

14. Mueller, C., Selenius, M., Theis, M., et al., Proc. Combust. Inst. 30(2): 2991(2005)

15. Li, B., Brink, A., and Hupa, M., Fuel Process. Technol. 105: 149(2013).

16. Eskola, A., Jokiniemi, J., Lehtinen, K., et al., Int. Chem. Recovery Conf., TAPPI Press, Atlanta, 1998, p. 469

17. Tavares, A. and Tran, H., TAPPI J. 80(12): 117(1997).

18. Tamminen, T., Kiuru, J., Kiuru, R., et al., TAPPI J. 1(5): 27(2002).

19. Mikkanen, P., Jokiniemi, J., Kauppinen, E., et al., Fundam. Adv. Innovation. Pulp Paper Ind. 95(322): 103(1999).

\section{ABOUT THE AUTHORS}

We chose this topic to gain an insight into where fume forms and its possible impact on recovery boiler operation. This research complements our previous modeling work in that the method has now been further developed to include alkali carbonates and to cover the superheater area of the boiler. The modeling results also have been partially validated against field measurements found in the literature.

The most difficult aspect of this work was the lack of available data in the literature for the validation of the modeling results. We addressed this problem by collaborating with researchers at the University of Toronto and using field measurement data.

According to the model, the majority of the fume mass forms already in high temperatures in the superheater area of the boiler. The next step is to validate the model with recent experimental results in a recovery boiler.

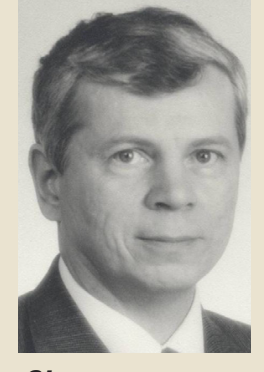

Oksanen

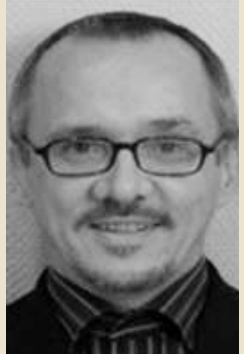

Välimäki

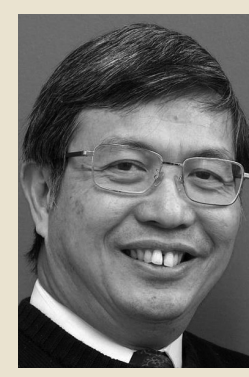

Tran
Once this modeling method has been successfully developed, it could be a useful tool for boiler manufacturers to use in their boiler design. Additionally, pulp mill engineers might be able to use it to optimize boiler operation.

Leppänen is a Ph.D. student and Oksanen is professor, Tampere University of Technology, Tampere, Finland. Välimäki is project manager, Metso Power Oy, Tampere, Finland. Tran is professor at the University of Toronto, ON, Canada. Email Leppänen at aino.leppanen@tut.fi. 


\section{RECOVERY BOILER}

20. Tamminen, T., Laurén, T., Janka, K., et al., TAPPI J. 1(6): 25(2002).

21. Janka, K., Wallén, J., and Backman, R., Pulp Pap. Can. 105(1): $\mathrm{T} 15(2004)$.

22. McKeough, P., Int. Chem. Recovery Conf., TAPPI Press, Atlanta, 2010. Available online at www.tappi.org/Downloads/ConferencePapers/2010/2010-TAPPIPAPTAC-International-Chemical-RecoveryConf/10ICRC09.aspx.

23. Saturnino, D., "Modeling of kraft mill chemical balance," Ph.D. thesis, University of Toronto, ON, Canada, 2012.

24. Jokiniemi, J. and Sippula, 0., "Modelling fine particle formation and alkali metal deposition in BFB combustion," Finnish-Swedish Flame Days 2009, Finnish Flame Research Committee (FFRC), 2009. Available online at www.ffrc.fi/FlameDays_2009/1A/ JokiniemiPaper.pdf.

25. Christensen, A. and Livbjerg, H., Aerosol Sci. Technol. 25(2): 185(1996).

26. Jöller, M., Brunner, T., and Obernberger, I., Fuel Process. Technol. 88(11-12): 1136(2007).

27. Bale, C.W., Bélisle, E., Chartrand, P., et al., CALPHAD 33(2): 295(2009).

28. Friedlander, S., Smoke, Dust, and Haze. Fundamentals of Aerosol Dynamics, Oxford University Press, New York, 2000.

29. Hinds, W., Aerosol Technology: Properties, Behavior, and Measurement of Airborne Particles, John-Wiley \& Sons, New York, 1999.

30. Herrmann, E., Lihavainen, H., Hyvärinen, A.-P., et al., J. Phys. Chem. A 110(45): 12448(2006).
31. Jokiniemi, J., Lind, T., Hokkinen, J., et al., Aerosols from Biomass Combustion, International Seminar, IEA Bioenergy Task 32 and Swiss Federal Office of Energy, Verenum, Zurich, Switzerland, 2001, pp. 31-39.

32. Kawaji, M., Shen, X.H., Tran, H., et al., Tappi J. 78(10): 214(1995).

33. Vakkilainen, E., Kraft Recovery Boilers - Principles and Practice, Valopaino Oy, Helsinki, Finland, 2005.

34. Hupa, M. and Hyöty, P., in Poltto ja Palaminen (R. Raiko, J. Saastamoinen, M. Hupa, et al., Eds.), Gummerus Kirjapaino Oy, Jyväskylä, Finland, 2002, pp. 522-556.

35. Tavares, A., Pulp Pap. Can. 97(10): 51(1996).

36. McKeough, P. and Vakkilainen, E.K., Int. Chem. Recovery Conf., TAPPI Press, Atlanta, 1998, p. 487.
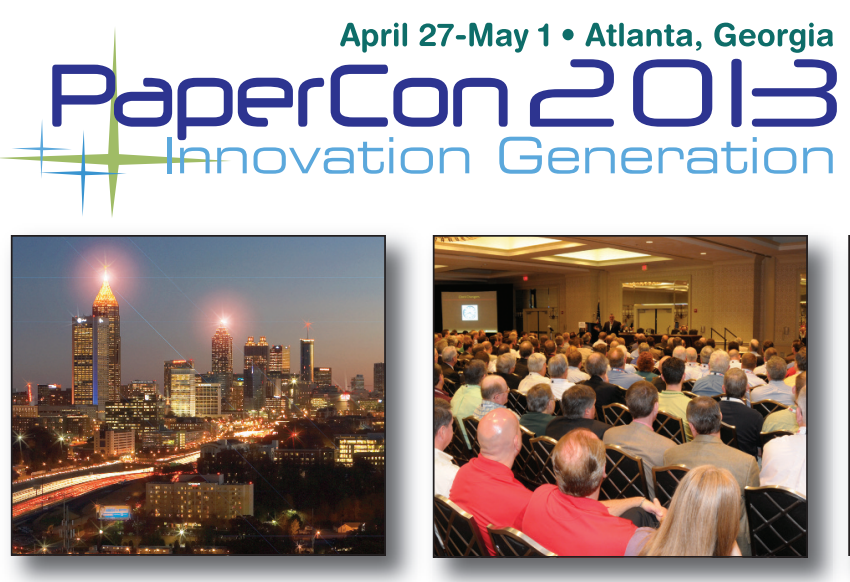

Designed by industry professionals, PaperCon brings together CEOs, mill managers, superintendents, scientists, process engineers and suppliers for the largest pulp and paper technical program in the world.
Joining PaperCon:

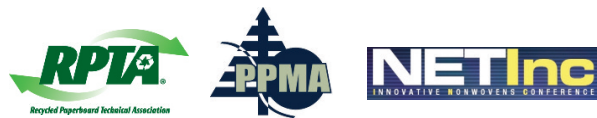

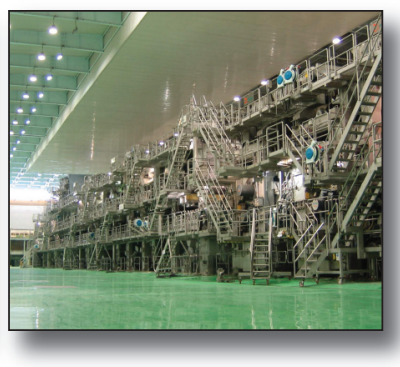

Program Highlights:

- NEW: Tissuez60 Forum

- NEW: NETInc (Innovative Nonwovens Conference)

- NEW: PPMA Labor/Management Relations

- Recycled Paperboard Production-Technical Seminar 